\title{
MEASUREMENT OF THE CONTENT OF MONOETHANOLAMINE DURING THE CONTROL OF THE TECHNOLOGICAL PROCESS OF DESULFURIZATION AND IN THE ENVIRONMENTAL OBJECTS
}

(C) A.Yu. Martynova, PhD in Technical Sciences, V.A. Saraeva, A.I. Larina (State Enterprise "Ukrainian State Research Coal Chemistry Institute (UKHIN)", 61023, Kharkiv, Vesnina St., 7, Ukraine)

The problem of cleaning coke oven gas from sulfur compounds, despite their recent decrease in the raw material base of coking, remains relevant in connection with the requirements to reduce sulfur dioxide emissions into the atmosphere. When using monoethanolamine for the purification of coke oven gas from sulfur compounds, production workers are faced with the problems of determining the exact concentration both in solutions and in coke oven gas and in environmental objects.

The article provides an overview of the currently existing methods for the quantitative determination of the content of monoethanolamine in liquid and gaseous media. The results of studies of the possibility of their use in the conditions of by-product coke production are presented, directions of improvement of the known methods are determined in order to eliminate the influence of accompanying components inherent in by-product coke production (in particular, ammonia, amines, phenols, etc.), which distort the analysis results. The authors describe the methods of increasing the selectivity of analytical methods for determining the content of monoethanolamine in:

- coke oven gas - based on the absorption of the test substance from coke oven gas by a solution of orthoboric acid, followed by its determination in a solution with $p$ nitrophenyldiazonium;

- the air of the working area under the conditions of by-product coke production - it was proposed to eliminate the negative effect of hydrogen sulfide and phenol using an absorber containing a sodium hydroxide solution located in front of the absorber with a hydrochloric acid solution for monoethanolamine (a revised measurement procedure with additions set out in accordance with the requirements of the current legislation in the field of metrology and established metrological characteristics, agreed by the Chief Sanitary Doctor of Ukraine).

The directions of research necessary for the development of a method for determining the content of monoethanolamine in process waters of coke-chemical production are outlined.

Keywords: desulfurization, monoethanolamine, content determination, selectivity, ammonia, p-nitrophenyldiazonium, coke oven gas, complex compound, color intensity, photometry, measurements.

Corresponding author A.Yu. Martynova, e-mail: alla_martynova_aisim@ukr.net 